\title{
EL HIMNO A ZEUS DE CLEANTES
}

José Molina Ayala*

RESUMEN: El Himno a Zeus de Cleantes, por sus características formales y por su contenido, es un texto importante y peculiarmente interesante para comprender la época helenística.

PAlABRAS ClaVE: Himno a Zeus, Cleantes, época helenística, estoicismo, Naturaleza, religión, Calímaco.

ABSTRACT: Due to its structural aspects and content, Cleantes' Hymn to Zeus, is considered a significant and interesting text aiding our understanding of the Hellenistic era.

KEYwORDS: Hymn to Zeus, Cleantes, Hellenistic era, stoicism, nature, religion, Callimachus.

RECEPCIÓN: 11 de agosto del 2010.

ACEPTACIÓN: 7 de diciembre del 2010.
* Centro de Estudios Clásicos, Instituto de Investigaciones Filológicas, UNAM. 


\section{EL HIMNO A ZEUS DE CLEANTES}

Generalidades de la época helenística Suele llamarse "época helenística" al lapso que transcurre entre dos muertes, la de Alejandro Magno y la de Cleopatra, es decir, aproximadamente del 323 a. C. al 30 d. C. Esta designación me parece acertada, ya que, por más convencionales que sean los límites de un período histórico, en este caso no pueden soslayarse las consecuencias que tuvo la expansión macedónica, ${ }^{1}$ de las cuales, tal

${ }^{1}$ A. Dihle, A History of Greek Literature. From Homer to the Hellenistic Period, 1994, London/New York, Routledge, p. 234: It is misleading to obscure the epoch-making character of this event (sc. la campaña militar de Alejandro), as has recently been the case in historical scholarship, by setting the date for the rise of Hellenism in the mid-fourth century $B C$ simply because the intellectual preconditions, and in some cases the early forms of new phenomena, were in place prior to Alexander. vez las más importantes y decisivas hayan sido, precisamente, la difusión e inculturación de la civilización helena a lo largo de todos los territorios conquistados. Tras la derrota del ejército de Marco Antonio a manos de Octavio, Cleopatra-la última descendiente de la dinastía de los Ptolomeos- daría fin con su propia muerte a un modelo económico y político que debió sucumbir, como tantos otros, a la hegemonía del imperio romano.

Por supuesto, no se trata de una época decadente ni, mucho menos, de una mera "excrecencia" de la Grecia clásica. Por el contrario, deben sorprendernos las soluciones que los hombres de aquellos tiempos encontraron para arrostrar las dificultades 
que implicaron la nueva configuración de la sociedad -piénsese tan sólo en los problemas del cosmopolitismo, de las migraciones, de las constantes guerras entre ejércitos, formados principalmente de mercenarios, y del continuo intercambio económico-, la crisis de las ideas que hasta entonces prevalecían, y la génesis, la apropiación y el desarrollo de otra cosmovisión. Hay que resaltar, más que nada, el gran atrevimiento y el mérito que supuso renunciar a los criterios tradicionales y someter todo al análisis del raciocinio. Consecuencia natural de este arrojo fue, por ejemplo, el desarrollo técnico y científico, de una magnitud que no volvió a verse sino hasta el siglo diecinueve de nuestra era; el solo nombre de Arquímedes debiera servir como emblema del progreso de entonces, para no hablar del "astrónomo" Arato, ni de su gran comentarista Átalo de Rodas, ni del controvertido matemático Hiparco de Nicea, ni de Aristarco de Samos, el Copérnico de la Antigüedad, de quien el mismo Arquímedes afirma (y rechaza) su teoría heliocéntrica. ${ }^{2}$ Pero, es preciso insistir, si todo entró en crisis, también todo fue puesto bajo la lente del lógos: ${ }^{3}$ la literatura y la religión, la filosofía y la política,

${ }^{2}$ T. Heath, Aristarcus of Samos, the ancient Copernicus, 1913, Oxford, At The Clarendon Press, p. 301.

${ }^{3}$ P. C. Tapia Zúñiga, "La areté en la época helenística”, Nova tellus, 9-10, 1991-1992, pp. 289-301. el conocimiento y la ética, el hombre mismo. Así se explican la irrupción de formas alternativas de pensamiento, las más nuevas y variadas escuelas filosóficas, las inusitadas modas literarias, el desarrollo de nuevas tecnologías y el progreso de las distintas ciencias, etcétera.

No es, pues, una época "menor" en la historia de la cultura. Más aún, ya en la época imperial, Octavio Augusto decidió también llevar el helenismo a los territorios conquistados por Roma, de manera que lo sucedido en la época helenística no es insignificante para lo que llegó a ser (eso que se dice ser) la civilización occidental, que en mayor o menor medida, y para bien o para mal, es todavía la nuestra. Además, ahora que todos se llenan la boca con la "globalización", no será inútil asomarnos a aquella primera expansión generalizada de un modelo cultural.

\section{Cleantes y el estoicismo}

Cleantes nació hacia el 331 o 330 a. C., según los pocos datos que tenemos, gracias a Diógenes Laercio, ${ }^{4}$ en la Tróade, en la ciudad de Assos; fue primero boxeador $y$, después de conocer, en Atenas, a Zenón de Citio, se dedicó a la filosofía durante el día y a trabajar durante las noches; tras una

${ }^{4}$ D. L., VII, 168-176. 
NOTAS

inflamación de las encías, se dejó morir de hambre, pues, según él, en el año 230 o 229 a. C., ya había vivido demasiado.

Estos pequeños datos nos hacen ver, por una parte, la movilidad que había en la época helenística; en efecto, los hombres ya no pertenecen a la polis tradicional, sino son "ciudadanos del mundo"; viajan, cambian de residencia; en cualquier ciudad se sienten como en la suya, con tal de que ésta comparta ciertos elementos comunes a todas, como los gimnasios, las palestras, el teatro, la lengua, las costumbres, etcétera. No es mínima la influencia que empiezan a ejercer las culturas no griegas en la ecumene; sin embargo, ésa será mínima, si se expresa por vías distintas del helenismo. De hecho, discernir los elementos extraños a la tradición griega no sería una pequeña labor de cualquier investigación que se emprendiera a propósito de esta época. ${ }^{5}$ Por otra parte, aun si se toma como falsa la Vida de Cleantes de Diógenes Laercio, ésta refleja que, en la época helenística, el individuo emerge con una mayor independencia con respecto a su origen, a su posición social, a su oficio. Se han transtornado las coordenadas que orientaban a los ciudadanos de la época clásica y comienzan a fraguarse otras

${ }^{5}$ Sobre el origen no griego del estoicismo, cfr. E. Elorduy, El estoicismo, 1972, Madrid, Gredos (Biblioteca hispánica de filosofía), t. I, pp. 25-73. categorías para pensar sobre el hombre; por ejemplo, la propiedad, o al menos la "propiedad" sobre el propio cuerpo será punto de arranque para reflexiones estoicas sobre el valor del ser humano y para la ulterior elaboración del concepto de persona. ${ }^{6}$

Al margen de las tradiciones filosóficas de la Academia y del Liceo, dirigidas esencialmente a las clases privilegiadas, las nuevas filosofías, en especial el epicureísmo, el estoicismo y el cinismo, ${ }^{7}$ concebidas no sólo como sistemas de pensamiento, sino, más bien, como formas de vida, se dirigieron a una capa más amplia de la población. ${ }^{8}$ Las diversas escuelas buscarán que el individuo, al margen de las circunstancias, consiga la felicidad en sí mismo; así, los estoicos la buscarán en la impasibilidad; los epicúreos en la imperturbabilidad; los cínicos en la indiferencia; los escép-

${ }^{6}$ A. A. Long, "Stoic Philosophers on Persons, Property-ownership and Community", en R, Sorabji (ed.), Aristotle and after, 1997, London, Institute of Classical Studies, School of Advanced Study, University of London (Bulletin of the Institute of Classical Studies Supplement, 68), pp. 13-31.

${ }^{7}$ No pasa inadvertido que el cinismo tuvo su origen antes de la época helenística: aquí lo menciono por su carácter popular, dado que proponía más una manera de vivir que un sistema de pensamiento, y porque ciertamente la influencia de su crítica social perduró durante la época helenística. Por lo demás, en esta época se desarrolla el género de la sátira Menipea, tan relacionada con esta "escuela".

${ }^{8} \mathrm{P}$. Hadot, ¿Qué es la filosofía antigua?, 1998, México, Fondo de Cultura Económica, p. 122-3. 
ticos, en la suspensión del juicio. Todas estas escuelas, incluso la de los pitagóricos, ${ }^{9}$ comparten el reto de dar respuesta a las nuevas interrogantes surgidas tras las conquistas de Alejandro. Evidentemente, no es el lugar para desarrollar los principios de cada una de las escuelas, ${ }^{10} \mathrm{y}$ convendría sujetarse al estoicismo, en general, y más específicamente al estoicismo de Cleantes.

El estoicismo recibe su nombre debido a que su fundador, Zenón de Citio (ca. 344-262 a. C.); después de estudiar filosofía al lado del cínico Crates, de Estilpón, de Polemón y de Diodoro Crono, solía conversar y dar sus lecciones bajo la columnata más importante de Atenas, la $\Sigma \tau$ oò

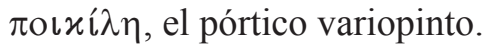

Ahora bien, aunque el estoicismo fue, entre otras cosas, un sistema de pensamiento, sus doctrinas no fueron siempre homogéneas, sino que se modificaron tras el debate con las otras escuelas. Así pues, en términos generales, se puede decir que el

${ }^{9}$ Debe pensarse aquí en filósofos pitagóricos de época helenística, que atribuían sus obras a Pitágoras mismo, o a pitagóricos tales como Arquitas de Tarento, Filolao o Timeo, cfr. A. Dihle, op. cit., p. 245.

${ }^{10}$ Una excelente introducción a la filosofía de la época helenística es David Sedley, "The Protagonist", en Malcolm Schofield, et al. (eds.), Doubt and Dogmatism. Studies in Hellenic Epistemology, 1980, Oxford, At Clarendon Press, 1980, pp. 1-19. estoicismo tuvo tres períodos: el temprano, el intermedio y el tardío. Zenón, Cleantes y Crisipo dominan el período temprano; Posidonio (c. 135-50 a. C.) y su maestro Panecio (c. 185-110 a. C.) son los personajes más importantes del intermedio; mientras que en el tardío destacan Epicteto ( $\mathrm{ca}$. mediados del s. I d. C.), Séneca (4-65 d.C.) y Marco Aurelio (121-180 d. C.).

Debe tenerse en cuenta que, como las otras escuelas, el estoicismo es una filosofía que, frente al desarrollo de las otras ciencias, se vio obligada a hacerse más sistemática; para ello, dividió su estudio en tres disciplinas principales: la física, la lógica y la ética. En términos muy generales, puede destacarse que gracias a ellos aparecieron en el horizonte filosófico problemas que ya no abandonaron la filosofía; por ejemplo, la libertad, el determinismo, el destino, la providencia, el eterno retorno, las pasiones, etcétera. Conviene señalar, como una de sus doctrinas de mayor importancia en dicho sistema, considerar a la física como equivalente de la metafísica y de la teología; es decir, para el estoicismo, sólo existe el ser material y todas las realidades que en otro tiempo Platón y Aristóteles consideraron como trascendentes o inmateriales (tales como Dios, el conocimiento o la virtud), pudieron ser explicados en términos mecanicistas. 
NOTAS

Resalta, ante todo, la primacía que tuvo la ética como centro de las preocupaciones de los estoicos, sobre todo de Zenón y de Cleantes. En efecto, el trabajo filosófico de Zenón se concentró en los problemas éticos, considerando como principio básico "vivir en conformidad"; este principio quedó más especificado por Cleantes, el segundo escolarca, quien añadió "vivir en conformidad con la naturaleza". Sin embargo, fue Crisipo ( $c a$. 280-206 a. C.), a quien se le denomina "el segundo fundador" y por quien se definió lo que se conoce como "estoicismo ortodoxo", quien sistematizó más sólidamente las intuiciones filosóficas de sus predecesores, apuntalándolas con el rigor lógico de los argumentos y haciéndolas capaces de sostener un debate frente el criticismo de los peripatéticos y de los académicos. A la postre, fue quizá el estoicismo la escuela de mayor influjo en la sociedad de la época helenística.

Ahora bien, el caso específico de Cleantes reviste particular importancia, si se considera que estuvo al lado de Zenón durante muchos años y que fue escolarca durante treinta y dos; sin embargo, para nuestra degracia, las obras de Cleantes corrieron la misma suerte que las de otros filósofos de su época; es decir, fuera de algunas pocas obras y de algunos fragmen- tos, están todas perdidas. ${ }^{11}$ ¿Cómo es posible, escapando de las generalizaciones, comprender el pensamiento estoico de Cleantes, si no se cuenta con sus obras?

\section{El Himno a Zeus de Cleantes} (Stob., I, 25, 3-27, 4 = SVF, I, 537)

El Himno a Zeus de Cleantes, es, por su forma y contenido, texto privilegiado para comprender la época helenística, al menos en lo que representa su primera etapa, ${ }^{12}$ y específicamente en lo que toca al estoicismo del filósofo de Assos.

Éstos son los versos, seguidos de una traducción que, espero, ayudará a vislumbrar lo que implica el estudio de los textos de la época helenística:

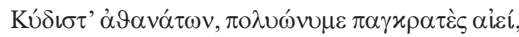

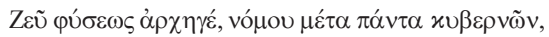

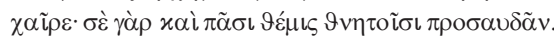

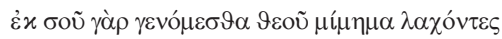

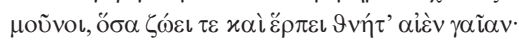

${ }^{11}$ D. L., VII, 174-175. Algunos títulos de sus obras son: El tiempo; El fisismo de Zenón; Exégesis de Heráclito; La sensopercepción; El arte; Contra Demócrito; Contra Aristarco; El impulso natural; Los dioses; El himeneo; La honestidad; Las virtudes; El amor; La libertad; Politico; La justicia; La educación; La amistad; El placer; La dialéctica; Los predicados, La igualdad de la virtud del hombre y la mujer, etcétera. En general, sobre el estado de la cuestión de las fuentes de los filósofos helenísticos, cfr. J. Mansfeld, "Sources", en K. Algra et al. (eds.), The Cambridge History of Hellenistic Philosophy, 1999, Cambridge, Cambridge University Press.

${ }^{12}$ Con respecto a las tres etapas de la época helenística, cada una, más o menos, de un siglo de duración, cfr. A. Dihle, op. cit. pp. 234-5. 


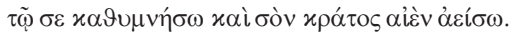

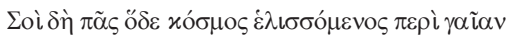

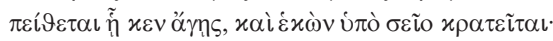

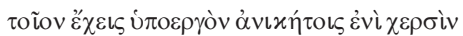

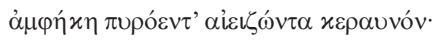

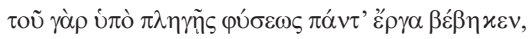

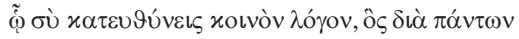

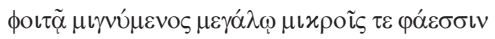

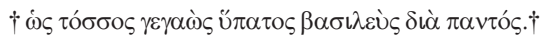

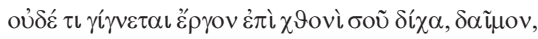

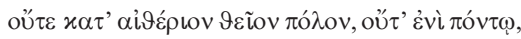

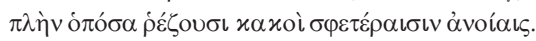

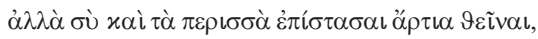

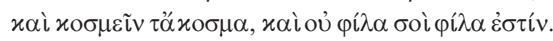

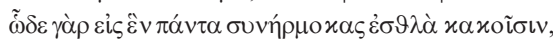

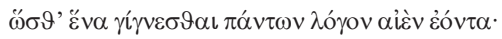

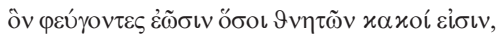

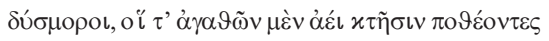

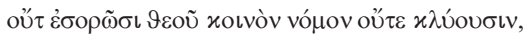

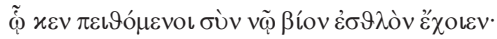

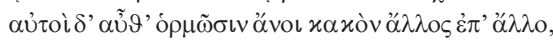

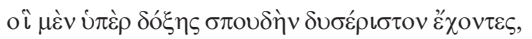

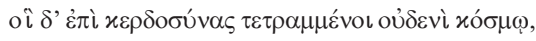

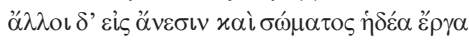

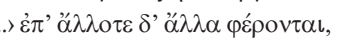

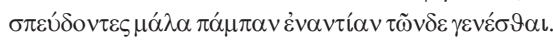

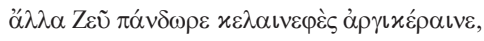

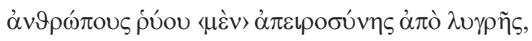

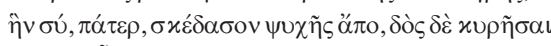

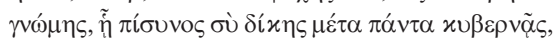

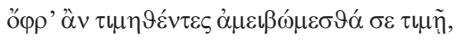

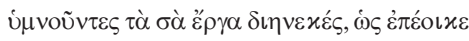

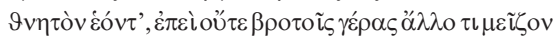

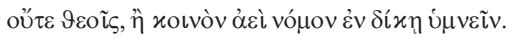

Gloriosísimo entre los inmortales, de muchos nombres, siempre todopoderoso

Zeus, conductor de la naturaleza, gobernando con ley todas las cosas,

salud: es justo que a ti cualquier mortal te invoque.

En efecto, de ti nacimos, habiéndosenos asignado ser imágenes de dios,

únicos, en todo lo que vive y se arrastra sobre la tierra; por eso te cantaré constantemente y tu poder siempre alabaré.

Ciertamente a ti, todo este orden, girando en torno a la tierra, te obedece, de la manera que rijas, y voluntariamente es dominado por ti; así tienes, útil, en tus invencibles manos, el ardiente y siempre viviente rayo de doble filo; pues por su golpe todas las obras de la naturaleza han sucedido;

con él, tú rectificas la razón común, la cual a través de todo

avanza, mezclando las luces pequeñas con la grande... $\sim$ cuán grande te has hecho supremo rey a través de todo

Ninguna obra surge sobre el suelo sin ti, dios, ni en la etérea bóveda divina, ni en el mar, excepto todas las cosas que ejecutan los malvados por sus insensateces.

Pero tú sabes hacer proporcionado lo excesivo y ordenar lo desordenado, y lo no querido, para ti es querido.

Pues de esta manera has ajustado todas las cosas en una sola, lo bueno con lo malo,

de manera que la razón de todo resulta ser siempre una sola;

a la cual rehuyendo renuncian todos los que de los mortales son malvados,

desdichados, y quienes siempre están deseando la posesión de los bienes

ni observan la ley común de dios, ni la escuchan, obedeciendo a la cual tendrían una vida buena junto con intelecto;

ellos, por el contrario, se lanzan insensatamente al mal uno contra otro,

unos, por la fama, teniendo un afán ineluctable, otros, por astucias, dirigidos a ningún orden, otros hacia el desenfreno y hacia las obras placenteras del cuerpo

$<\ldots . .>$ de aquí para allá son llevados

apresurándose muchísimo por que suceda lo contrario.

Pero Zeus, generoso, que cubres el cielo de nubes negras, el de rayo fúlgido,

ampara a los hombres de la deplorable inexperiencia, a la cual, tú, padre, dispersa, y concede que obtengamos

juicio, en el cual confiado tú gobiernas todo con justicia,

para que, habiéndote honrado, seamos recompensados con honra,

cantando tus obras perpetuamente como conviene que el mortal esté, puesto que ningún otro don para los mortales hay más grande

ni para los dioses, que cantar siempre en justicia la ley común. 
NOTAS

Sólo la "inexperiencia" y la falta "de juicio" (para usar los mismos términos de Cleantes, $\lambda u \gamma \rho \eta ́, \gamma v \omega ́ \mu \eta)$, evitarían el asombro ante estos versos, y me refiero a los versos griegos, de cuya forma y contenido mi traducción es un mero esbozo. En efecto, estamos frente a una obra de arte, un poema, es decir, ante un texto que obedece a determinadas reglas para su elaboración, y que, al mismo tiempo está pletórico de sentidos.

Ahora bien, el himno como género se remonta a la tradición de los Himnos homéricos, donde el contenido religioso, expresado en la alabanza de las hazañas de los dioses, está unido íntimamente a la forma épica de los hexámetros. Posteriormente, el himno religioso ha debido sufrir una transformación de acuerdo con las crisis que experimentó la religión griega, hasta llegar a Calímaco, donde lo religioso es mero pretexto para exhibir los singulares valores de la literatura alejandrina: la erudición, el virtuosismo poético, la crítica literaria. Sin embargo, no parece que el Himno a Zeus de Cleantes tenga meras pretensiones literarias, pues en su contenido se vislumbra una religiosidad, que podría provisionalmente denominarse "filosófica", alejada de Homero, pero de un peculiar sentido que todavía está por determinarse. Por otro lado, el contenido está sometido a cánones de escritura que no son "ingenuos" o espontáneos, y más allá de la significación que puedan tener las formas para establecer el género del poema; parece, según el testimonio de Séneca, que hay intenciones y efectos didácticos en la escritura en verso, "pues, como decía Cleantes, así como nuestro aliento produce un sonido más claro cuando una trompeta, habiéndolo contraído por los espacios angostos de un largo canal, lo suelta finalmente por una salida más abierta, así la estrecha necesidad del poema hace más claros nuestros sentidos". ${ }^{13}$

Entonces, en cierta forma y de manera apresurada, ¿podemos decir que estamos frente a un poema didáctico, acaso a la manera del De rerum natura de Lucrecio?

En cuanto al contenido, allí están los principales temas de toda filosofía: dios, hombre y mundo; están también los temas más significativos de la filosofía estoica, la ética, la física, y aunque en mucho menor medida, la lógica; de manera específica, están los temas del destino, de la providencia, de la virtud, de la libertad, etcétera. Detrás de todo el poema, se puede suponer la siguiente intención: frente

${ }^{13}$ Sen., Ep., CVIII: “Nam”, ut dicebat Cleanthes, "quemadmodum spiritus noster clariorem sonum reddit, cum illum tuba per longi canalis angustias tractum patentiore nouissime exitu effudit, sic sensus nostros clariores carminis arta necessitas efficit". 
a la decadencia de los criterios hegemónicos tradicionales, Cleantes buscó un fundamento universal, o mejor dicho, cosmopolita, y lo encontró en "la naturaleza", a la que había que conocer, o en "el destino", al que había que someterse, o en Zeus, en el Zeus de los estoicos, "el Zeus de Cleantes es vó $\mu$ os (ley universal),

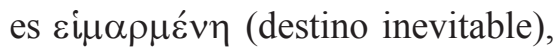

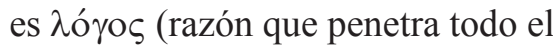
universo) y es $\pi \rho o_{\text {vol } \alpha}$ (providencia casi amorosa)"; ${ }^{14}$ por todo ello, un Zeus digno de un canto. Cleantes buscó, pues, junto con los otros estoicos, una revaloración sui generis de la religión tradicional, como consecuencia obligada de conocer y seguir a la naturaleza, lo cual era, precisamente, base de la felicidad. Hay que decir, además, que es muy posible que el poema en sí mismo quiera ser también él, de alguna manera, un universo ordenado por Zeus, ${ }^{15}$ como el cosmos de los fenómenos de Arato, donde frecuentemente el Cielo es Zeus, y Zeus, un padre providente -casi igual que el de Cleantes-.

\footnotetext{
${ }^{14}$ Bern Effe, en Pedro C. Tapia Zúñiga, "Diosemia y signos visibles", en Revista Universidad Nacional, 586-587 (noviembre-diciembre), 1999, pp. 68-74.

${ }^{15}$ D. Gigli Picsardi, "L'opera letteraria e l'Universo. Cleante, Crisippo, Elio Aristide", Prometheus, XIII, 1987, 28-36.
}

\section{Origen y transformación del poema. Cuestiones pendientes}

Pero ni el estoicismo en general, ni Cleantes en particular, nacieron, como se dice, "ni de árbol ni de piedra". ${ }^{16}$ Tampoco el Himno a Zeus vino de la nada ni, por supuesto, fue a parar en la nada. En efecto, los estoicos como las otras escuelas helenísticas, abrevaron de la tradición remota y próxima de la filosofía. Así, los epicúreos se nutrieron preponderantemente del atomismo de Demócrito y Leucipo; los escépticos, en los llamados diálogos aporéticos de Platón; los cínicos, en ciertas actitudes socráticas en contra de las convenciones sociales; los estoicos se incendiaron con el fuego de Heráclito.

Para la exposición y elaboración de su pensamiento, como dijimos, los filósofos del Pórtico no sólo no echaron por tierra las tradiciones precedentes, sino, además, tuvieron un continuo debate con las otras escuelas contemporáneas, que no pocas veces los llevaron a modificar su pensamiento o a expresarlo de una manera más consistente, valiéndose incluso de metodologías ajenas. Este debate de ideas originaría, a la postre, el eclecticismo de las etapas filosóficas posteriores. ¿Qué doctrinas del poema fueron desarrolladas por los mismos

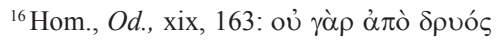

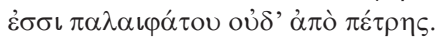


NOTAS

estoicos, de acuerdo con los fragmentos que nos han llegado? ¿Qué doctrinas fueron contradichas o seguidas por las distintas escuelas helenísticas? ¿Qué otros textos, anteriores, contemporáneos o posteriores, pueden contribuir a la mejor comprensión del poema? Tal vez habría que leer el poema de Cleantes a trasluz del Timeo de Platón, más que en referencia a las doctrinas de Heráclito. Sin embargo, éstas y otras preguntas esperan una respuesta, una investigación que no puede hacerse en este espacio.

Asimismo, podría investigarse también la influencia posterior del Himno a Zeus aun en tradiciones ajenas al estoicismo. Se habría de indagar, entonces, la recepción que tuvo el poema en posteriores escritores y poetas. Valga mencionar, por ejemplo, al gran pensador Pablo de Tarso, sí, o San Pablo, que introduce a la revelación del Nuevo Testamento un verso del Himno a Zeus de Arato ${ }^{17}$ sin embargo, dicho verso arateo concuerda casi literalmente con un verso de Cleantes: $\dot{\varepsilon} \varkappa$ бoũ

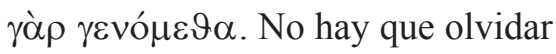
que tenemos este poema porque se conservó gracias a Estobeo, un obispo del siglo $\mathrm{V}$ d. C., que lo consignó en sus Églogas.

En cuanto a la forma, no hay que pasar por alto el vocabulario, la métrica, el tono épico del poema y demás

${ }^{17}$ Hch, 17, 28-29. recursos de la retórica. Habría que analizar todo minuciosamente, y acaso, sólo entonces, se pueda clasificarlo debidamente. Pero tratándose de un poema de la época helenística esto no basta. En efecto, tenemos como paradigma de la estética alejandrina -nacida al amparo de las cortes ptolemaicas-, las obras de Calímaco de Cirene (ca. 305-240 a. C.), de quien Cleantes es contemporáneo.

¿Cómo describir y juzgar en pocas líneas la obra del poeta bibliotecólogo, filólogo (=erudito), lexicólogo, mitólogo Calímaco? En ella no hay palabra ociosa; todas están llenas de sapiencia; de alusiones veladas y manifiestas a la tradición léxica; de crítica histórica y literaria; muchas de esas palabras no se escribieron sin ironía. Incluso la posición de un vocablo dentro de un hexámetro le sirve al poeta de Cirene para hacer sarcasmos a costa de Homero. Ora describe un mito antiguo, el menos conocido; ora juzga entre dos versiones del mismo mito; ora adula a la esposa de su patrono; ora critica los enormes fárragos, el gran mal del libro grande, en favor de la brevedad; ora inventa palabras o recupera las ya olvidadas. En fin, de la gran prisión que suponía toda la tradición literaria, Calímaco encontró la salida en esa exquisita poesía dirigida al público culto, en ese alarde de su virtuosismo poético y de conocimiento. Por cierto, él también 
compuso un Himno a Zeus, su primer himno.

En esta manera de hacer literatura se inscribe el Himno de Cleantes. Por tanto, cada palabra hay que pesarla en la balanza de los himnos homéricos y órficos; se debe juzgar el poema a contraluz con la revaloración de Zeus llevada a cabo por Hesíodo; se precisa también la comparación del poema con las elegías de Solón. Habría que examinar, dentro del género de los himnos, cuanta obra pueda arrojar luz sobre su recta interpretación literaria, sin dejar de lado, por supuesto, los himnos de Calímaco, sin olvidar el Himno a Zeus que el poeta astrónomo Arato de Solos ( $c a$. 315-245 a. C.) puso al principio de sus Fenómenos. Tal vez tampoco haya que olvidar los himnos escritos en la Antigüedad tardía por Juliano y por Proclo.

Restaría, además, hacer una valoración del texto como una plegaria; es decir, se precisa de una interpretación plausible del elemento religioso dentro del texto. También es cierto que la época helenística involucra aspectos que tienen que ver mucho con nosotros. Para decirlo con Carlos Lévy:

Se ha explicado el desarrollo reciente de los estudios sobre los filósofos helenísticos por las impresionantes semejanzas entre su época y la nuestra. El mismo cosmopolitismo, la misma referencia a la naturaleza erigida en norma absoluta -desgraciadamente, sin Carnéades alguno, para revelar los peligros de ello-, la misma búsqueda de la felicidad individual, la misma forma de cultura, más preocupada de erudición que de creación. El abandono de la utopía, la renuncia a encontrar un sentido a la historia, la rehabilitación del sujeto, conducen a la búsqueda de una sabiduría, incluso si el término se ha vuelto demasiado anticuado para parecer pertinente, $y$ facilitan el redescubrimiento intuitivo de algunos temas helenísticos. ${ }^{18}$

Dado que apenas es posible hacerse una idea adecuada de la época helenística sin estoicismo y sin Calímaco, vale la pena leer y releer este Himno a Zeus de Cleantes, pues en él confluyen, de manera paradigmática, la tradición estoica del pensamiento y la herencia estética alejandrina. Sobre todo, habiendo comprendido el texto, sus implicaciones, sus relaciones, su influencia, sus orígenes, hay que responder a las preguntas: ¿qué nos puede decir todavía a nosotros? ¿Cómo deberíamos entenderlo? ¿Cómo podemos reaccionar ante él, una vez que hemos comprendido mejor sus implicaciones?

${ }^{18} \mathrm{C}$. Lévy, Les philosophies hellénistiques, 1997, Paris, Librairie Général Française (Le livre de poche), p. 222. 
CITAM Derechos Reservados.

La reproducción total o parcial de este artículo se podrá hacer si el ITAM otorga la autorización previamente por escrito. 